\title{
Matemática, filosofía y pensamiento simbólico en Leibniz
}

\author{
Mathematics, Philosophy and Symbolic Thought in Leibniz
}

PEDRO A. VIÑUELA VILLA*

\begin{abstract}
Resumen: Según Leibniz, el pensamiento humano es en su mayor parte simbólico porque se sirve de signos en lugar de considerar directamente las cosas o las ideas mismas. El presente artículo se propone mostrar la importancia y radicalidad de esa tesis, explicando, en primer lugar, en qué consiste básicamente la cogitatio symbolica, para examinar después, en segundo lugar, cómo se proyecta en matemática y en filosofía. Para finalizar, se establecen algunas conclusiones sobre la trascendencia de dicha doctrina y sobre su ámbito de aplicación.
\end{abstract}

Palabras clave: simbólico, pensamiento, conocimiento, matemática, filosofía, razonamiento.

\begin{abstract}
According to Leibniz, human thought is mostly symbolic because it uses signs instead of considering directly the things or ideas themselves. In order to show how important and fundamental that thesis is, the paper intends to explain, firstly, what symbolic cogitatio basically is, and, secondly, to examine its influence on mathematics and philosophy. Finally, some conclusions about the transcendence of this doctrine and the extent of its applicability are established. Keywords: symbolic, thought, knowledge, mathematics, philosophy, reasoning.
\end{abstract}

Recibido: 10/07/2017. Aceptado: 27/10/2018.

* Licenciado en Filosofía, Doctor en Filosofía e Ingeniero Industrial. Profesor en la Universidad Europea de Madrid (pavinuela@gmail.com). Líneas de investigación: Filosofía moderna, filosofía de la matemática y filosofía del lenguaje. Publicaciones recientes: Viñuela, P. (2018), Lenguaje, arte y filosofía en Kant, Madrid: Ápeiron Ediciones; Viñuela, P. (2018), «On Kant's Arithmetical Construction of Concepts», en: V. Waibel, M. Ruffing y D. Wagber (eds.): Natur und Freiheit / Nature and Freedom. Proceedings of the XII. International KantCongress (five volumes). Berlín/Boston: Walter de Gruyter, pp. 1449-1457; Viñuela, P. (2017), De la revolución copernicana al mundo newtoniano, Madrid: Ápeiron Ediciones; Viñuela, P. (2016), «Perception, Presumption and Perspectivism in Leibniz», en: W. Li (ed.): “Für unser Glück oder das Glück anderer”. Vorträge des X. Internationalen Leibniz-Kongresses (Band IV), Hildesheim: Georg Olms Verlag, pp. 335-348. 
Qualem cogitationem caecam vel etiam symbolicam appellare soleo, qua et in Algebra et in Arithmetica utimur, imo fere ubique.

G. W. Leibniz ${ }^{1}$

\section{Introducción}

Entre los nombres con que Aristóteles bautizó la prima philosophia, que tras su muerte

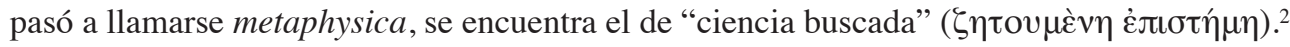
Es realmente notable que una denominación tan temprana haya anticipado con tanta clarividencia el sino de la metafísica durante milenios, ya que ha profetizado fielmente, por siglos, el carácter siempre provisional, nunca acabado, que la ha caracterizado. Sorprende por ello que ese nombre no se haya impuesto a los demás, pues se trata del que mejor refleja la condición de búsqueda permanente, nunca cerrada del todo, que distingue específicamente a la metafísica de las restantes actividades del espíritu. ${ }^{3}$

Leibniz reconoce por eso que la metafísica sigue siendo en su época, como en los tiempos de Aristóteles, una ciencia anhelada pero jamás encontrada (desiderata seu quaesita), un saber que continúa estando entre las ciencias que se buscan (adhuc inter quaerenda mansisse).${ }^{4} \mathrm{Y}$ lo que es peor, su falta de rigor y solidez amenaza con extenderse a las ciencias particulares que, como saber primero y arquitectónico, le están supeditadas. ${ }^{5} \mathrm{Y}$ así la distancia que separa la menesterosa realidad de la metafísica de su ansiada cientificidad se ha revelado insalvable. Decir, pues, que la prima philosophia es la ciencia del ser en general cuando los compendios de metafísica no hacen más que ofrecer nociones vagas, mera palabrería y distinciones puramente nominales, es abusar en exceso, según Leibniz, del nombre de ciencia. ${ }^{6}$ Por ello "la mayor parte de los que se complacen en el estudio de la matemática sienten aversión por el de la metafísica, ya que en aquélla encuentran luz, en ésta tinieblas".7

Leibniz, sin embargo, pretende arrojar la luz del método matemático sobre la oscuridad metafísica. El motivo lo confiesa él mismo: "siempre me pareció que era posible establecer en ella [filosofía] algo sólido mediante demostraciones claras [demonstrations claires]" 8 Sostiene, por esta razón, que si alguien quisiera escribir como matemático sobre metafísica o moral, nada le impediría hacerlo con rigor. ${ }^{9} \mathrm{Y}$ así, durante toda su vida, el formalismo lógico-matemático fue para él un paradigma al que aproximar el saber en general. Su characteristica universalis se inspira, de hecho, en ese modelo, así como en la premisa de que el modus operandi por defecto de la mente humana es de índole simbólica. El nuevo órgano de la ciencia tendrá que ser, consiguientemente, un sistema universal de caracteres

1 Meditationes de cognitione, veritate, et ideis, AA VI, 4B, 587-588. Para facilitar la remisión a las obras de Leibniz, se adoptan las siglas y abreviaturas convencionales de las ediciones originales según establece el proyecto Leibniz en Español (http://www.leibniz.es/siglas.html).

2 Cf. Met., III 2, 996b2-3; Met., XI 1, 1059b1, 13, 22, 25; Met., XI, 2, 1060a4, 6.

3 Vid. Aubenque, 2008, 211.

4 Cf. De primae philosophiae emendatione, et de notione substantiae, GP IV 468.

5 Vid. De primae philosophiae emendatione et de notione substantiae, GP IV 468.

6 Vid. Nouveaux Essais, IV 8 § 9, GP V 411-412.

7 De primae philosophiae emendatione et de notione substantiae, GP IV 468.

8 Systeme nouveau de la nature et de la communication des substances, GP IV 478.

9 Cf. Nouveaux Essais, II 29 § 12, GP V 242. 
que habrá de convertirse, a la postre, en la lengua conceptual de la filosofía. Gracias a ello, será posible aumentar extraordinariamente, a juicio de Leibniz, la capacidad inventiva del espíritu y transformar el razonamiento en un calculus ratiocinator.

Así pues, ese ambicioso proyecto llevó a Leibniz a tratar de cimentar el saber sobre bases formalistas y semióticas, punto de vista que se proyecta, como veremos a lo largo del artículo, en la forma en que concibe la matemática y la filosofía.

\section{El pensamiento simbólico}

Desde su juventud Leibniz estaba convencido de que sin caracteres el espíritu es incapaz de pensar y razonar con distinción. ${ }^{10}$ Aunque esta dependencia parezca en principio una enorme limitación, Leibniz creía que podía ser compensada con creces por medio de una sabia gestión de nuestras deficiencias y fortalezas a fin de optimizar nuestras disposiciones más favorables. Basta por ello "con que al considerar el proceder de nuestra alma seamos capaces de distinguir la fuente de nuestras debilidades, pues ese conocimiento nos proporcionará al mismo tiempo el conocimiento de los remedios [remedes]". ${ }^{11}$ Después de todo, si el espíritu, pese a todas sus limitaciones, juega bien sus bazas, puede resultar finalmente victorioso. $^{12}$

Ahora bien, nuestra mente, según Leibniz, opera casi siempre de manera ciega y simbólica debido a la finitud de nuestra intuitio. De ahí que nos resulte más fácil y cómodo razonar, en la práctica, con caracteres que tener que contemplar a cada paso las cosas o las ideas mismas. ${ }^{13}$ Esta es la razón por la cual la cognitio symbolica en el hombre es superior a la cognitio intuitiva, sobre todo cuando va acompañada del método característico.

\subsection{Cogitatio symbolica y cogitatio intuitiva}

En su ensayo Meditationes de cognitione, veritate et ideis, ${ }^{14}$ Leibniz postula - siguiendo la terminología cartesiana - ${ }^{15}$ una graduación cognitiva ascendente en claridad y distinción, desde la mayor oscuridad hasta la máxima nitidez. ${ }^{16}$ Según tal gradación, el conocimiento es oscuro o claro y el claro, a su vez, confuso o distinto. Y el conocimiento distinto puede ser adecuado o inadecuado, así como simbólico o intuitivo. Y cuando el conocimiento es al mismo tiempo adecuado e intuitivo, en la medida en que algo así es factible para el hombre, la cognición es sumamente perfecta (cognitio perfectissima).${ }^{17}$

Así pues, Leibniz contrapone, en el plano de la representación distinta, conocimiento simbólico y conocimiento intuitivo. Esta contraposición tiene la peculiaridad de asignar al

10 Vid. Dialogus (1677), AA VI, 4B, 22-23; Nouveaux Essais, II 21 § 73, GP V 197.

11 Nouveaux Essais, II 21 \$3, GP V 173-174.

12 Vid. Nouveaux Essais, II $21 \S 35$, GP V 172.

13 Vid. Meditationes de cognitione, veritate et ideis, AA VI, 4B, 587; Analysis linguarum (1678), AA VI, 4B, 102103; Nouveaux Essais, II $21 \S 35$, GP V 171-174.

14 Leibniz considera este opúsculo (Acta Eruditorum, 1684) la exposición definitiva de su gnoseología.

15 Vid. Nouveaux Essais, II 29 § 4, GP V 237/Leibniz, 1977, 296.

16 Vid. Discours de métaphysique, § 24, AA VI, 4B, 1567-1568.

17 Cf. Meditationes de cognitione, veritate et ideis, AA VI, 4B, 585-586. 
conocimiento humano intuitivo el lugar de límite interno e inmanente de la cognitio distincta. El conocimiento divino, en cambio, al ser puramente intuitivo, ${ }^{18}$ se sitúa en el extremo trascendente de la representación distinta, como límite externo del pensamiento simbólico ${ }^{19}$ En este sentido, la cognición simbólica, frente a la cognición puramente intuitiva, se presenta como una carencia originaria del conocimiento humano, a causa de la incapacidad de la mente para pensar siempre de forma simultánea (simul cogitare) la totalidad de las nociones parciales de que se componen las nociones complejas..$^{20}$ Porque la intuitio intellectualis se limita en el hombre a la aprehensión de la idea de las nociones simples, ${ }^{21}$ tal como tiene lugar en las definiciones adecuadas, en las que hay verdades primitivas de razón y, por ende, conocimientos intuitivos..$^{22}$ La cognitio intuitiva, en consecuencia, clausura el proceso de análisis lógico exhaustivo que hace posible fundamentar con rigor las verdades necesarias. En otras palabras, la visión de la naturaleza íntegra de la cosa analizada sella intuitivamente la descomposición lógico-conceptual de la noción, certificando así la verdad de la representación.

El conocimiento humano no se distingue, pues, del conocimiento divino por la intuición per se, sino por el carácter eminentemente finito de ésta. La cognición del hombre, por tanto, se diferencia específicamente por el hecho de que tiene que compensar por medio de símbolos la finitud de su intuitio. De ahí que Leibniz no se canse de repetir que nada es más frecuente y necesario en los hombres que la cogitatio symbolica. ${ }^{23}$ Pues, siendo una forma de pensar típicamente humana, no sólo está presente en el álgebra y la aritmética, sino "casi en todo" (imo fere ubique). ${ }^{24} \mathrm{El}$ conocimiento simbólico cubre entonces un inmenso espacio gnoseológico, ya que los símbolos aparecen allí donde la intuición no llega. ${ }^{25}$

Como veremos en las secciones siguientes, existen razones de peso para sostener que en los humanos la cognitio symbolica es superior a la cognitio intuitiva.

\subsection{Los signos y el pensamiento}

Leibniz parte de la premisa de que el pensamiento humano es esencialmente semiótico, ya que necesita signos para poder pensar y conocer. ${ }^{26}$ Pues las nudas facultades, sin el auxilio de los símbolos, apenas son capaces de traspasar el umbral de lo sensible y alcanzar la nitidez en la representación (cognitio distincta). ${ }^{27}$ Esto puede comprobarse fácilmente en la aritmética donde, a juicio de Leibniz, se necesitan signos incluso para ejecutar las operaciones más sencillas:

18 Según Leibniz, "únicamente Dios tiene la ventaja de tener sólo conocimientos intuitivos [connoissances intuitives]" (Nouveaux Essais, IV 17 § 16, GP V 472/Leibniz, 1977, 598).

19 Cf. Pombo, 1987, 115-119.

20 Vid. Meditationes de cognitione, veritate et ideis, AA VI, 4B, 587-588.

21 Leibniz afirma que "sólo vemos la idea íntegra [l'idée entiere] cuando nuestro conocimiento es claro en las nociones confusas o cuando es intuitivo en las nociones distintas" (Discours de métaphysique, § 25, AA VI, 4B, 1570/OFC 2 190).

22 Cf. Nouveaux Essais, IV 2 § 1, GP V 347/Leibniz, 1977, 439.

23 Cf. Demonstratio propositionum primarum, AA VI, 2, 481.

24 Cf. Meditationes de cognitione, veritate et ideis, AA VI, 4B, 587-588.

25 Cf. Meditationes de cognitione, veritate et ideis, AA VI, 4B, 588. Vid. Gensini, 1992, 116.

26 Cf. Fundamenta calculi ratiocinatoris, AA VI 4B 918-919. Vid. Favaretti, 2006, 86.

27 Cf. Favaretti, 2006, 86. 
Nadie puede, en efecto, calcular [computare], especialmente grandes números, sin nombres o signos numéricos [sine nominibus vel signis numeralibus], pues habría que imaginar distintamente en vez del número todas las unidades comprendidas en él. Pero ¿quién podría imaginar distintamente las unidades incluidas en 1.000.000.000.000 a menos de disponer de la edad de Matusalén? Y aunque pudiera llevarlo a cabo, al avanzar se olvidaría de las primeras. ${ }^{28}$

Leibniz viene a decirnos aquí que la imaginación y la memoria por sí solas, sin símbolos, no bastan para realizar cálculos elementales. Pero, cuando se apoyan en signos adecuados, pueden catapultar el sentido numérico hasta el infinito. ${ }^{29} \mathrm{Y}$ así, no sólo en aritmética, sino en general en todo razonamiento, los sistemas de signos, cuando son idóneos, ayudan a minimizar el gasto mental y el dispendio temporal, a la vez que incrementan sustancialmente las prestaciones cognitivas. De ahí que sea tan importante para Leibniz estudiar a fondo la conexión entre pensamiento y lenguaje. No es casual que proponga por ello como misión general del ars characteristica la investigación de la conexión entre signos y pensamiento, porque tal conocimiento es conditio sine qua non para la creación de un simbolismo universal que responda a los requerimientos de la inteligencia, a fin de que los hombres puedan razonar eficazmente con él de manera cómoda y exitosa. La cogitatio symbolica es, de este modo, la contrapartida natural, en el plano psicológico y epistemológico, de la characteristica universalis.

En este sentido, no nos alejamos de Leibniz si afirmamos que el hombre padece su finitud mental como una especie de esclavitud que tiraniza su vida consciente, obligándole a realizar actividades penosas que considera impropias de su condición y de las que, por tanto, desea liberarse. Leibniz está convencido de que en parte puede darse cumplimento a ese anhelo de emancipación cognitiva ideando dispositivos simbólicos y mecánicos que eximan al hombre del trabajo mental enojoso que experimenta como una auténtica condena. Una vía para lograrlo es mejorar y automatizar la cognición mediante la formalización del saber y el desarrollo de sistemas de signos apropiados. Un paso más en esa dirección lo constituye el diseño y construcción de dispositivos mecánicos capaces de simular las operaciones inteligibles y formalizables del razonamiento humano. Esta vía permite transitar de la automatización de procesos cognitivos in mente, mediante la adquisición por aprendizaje de hábitos operacionales, a la mecanización del razonamiento in machina mediante la simulación, en términos mecanicistas, de esos procedimientos en dispositivos de cálculo.

Leibniz, en suma, no sólo pretende desarrollar la characteristica universalis para automatizar la cognición humana mediante hábitos simbólico-procedimentales sino también para sustituir dichos procesos cognitivos mediante el diseño y construcción de aparatos mecánicos que automaticen el cálculo.

28 Demonstratio propositionum primarum, AA VI, 2, 481. Hobbes ya sostenía que "no hay posibilidad, sin palabras, de llevar la cuenta de los números" (Leviatán, Hobbes, 1996, 36).

29 Los signos ayudan a la memoria compendiando el proceso cognitivo y proporcionándole auxilio mnemotécnico (cf. Demonstratio propositionum primarum, AA VI, 2, 481). Asimismo, ayudan a la imaginación haciendo posible la consideración simultánea de pensamientos diversos para poder conectarlos entre sí (vid. Gensini, 1992, 117). 


\subsection{Pensamiento simbólico preteórico: el psitacismo}

Un error bastante extendido es el que restringe la doctrina leibniziana del pensamiento simbólico exclusivamente al ámbito de la lógica y la matemática. Que es un malentendido lo pone de relieve el hecho de que la cogitatio symbolica - junto a las percepciones y los apetitos de índole inconsciente- desempeña un papel clave en la psicología moral de Leibniz, en la que el filósofo trata de explicar cómo se relaciona el individuo con el bien moral y la virtud. ${ }^{30}$ En parte a esa equivocación se debe el que no se haya prestado suficiente atención al hecho de que la cognitio symbolica ya se manifiesta en el orden preteórico:

Así, todos los días podemos ver personas que, no viendo ninguna dificultad en utilizar palabras usadas en su lengua materna antes de haber aprendido su significación precisa, cambian la idea que le atribuyen casi tantas veces como la hacen intervenir en su discurso. ${ }^{31}$

De este modo, Leibniz está convencido de que el espíritu se conduce de forma simbólica y algorítmica desde el momento en que opera con lenguas naturales, puesto que a menudo funciona como un procesador automático de palabras vacías de contenido. Los hombres, en efecto, suelen emplear las palabras sin atender a su significado - ya sea porque lo ignoran, ya sea porque sencillamente no lo actualizan en el pensamiento al pronunciarlas -, repitiéndolas mecánica e irreflexivamente a la manera de un papagayo. Leibniz asocia así este tipo de comportamiento psicolingüístico con la habilidad de ciertos loros para imitar la voz humana. Lo llama psitacismo (psittacisme) 32 porque ya desde los tiempos de Aristóteles se sabe de aves capaces de emular sonidos lingüísticos, sin saber qué significan. Los orangutanes y otros monos, en cambio, aprenden "lenguajes" basados en gestos y símbolos sin ser capaces de hablar, pese a que disponen de órganos tan adecuados como los nuestros para la fonación. ${ }^{33}$ Por eso Leibniz afirma con sorna que el hombre se asemeja a un mono que habla como un loro (singe qui parle comme les perroquets). ${ }^{34}$

Herder expresa bien este punto de vista cuando distingue entre la palabra externa (el aspecto puramente acústico de la palabra transmitida por el aire) y la palabra humana propiamente dicha, la cual se origina en la interioridad del sujeto como signo de discernimiento claro. En su Ensayo sobre el origen del lenguaje (1770), afirma que es la posesión y el ejercicio de la razón lo que hace posible que el niño aprenda la lengua y que no pronuncie solamente palabras vacías de pensamiento, como hacen los loros. ${ }^{35}$ Porque, a pesar de que el

30 La psicología moral estudia la relación psicológica de los seres humanos con la moralidad, partiendo de la premisa de que algunas cosas son buenas/correctas mientras que otras son malas/incorrectas (cf. Arpaly y Schroeder, 2017, 1). Vid. Davidson, 2005.

31 Nouveaux Essais, II 29 § 9, GP V 240/Leibniz, 1977, 299. Filaletes, el portavoz de Locke, es el que se expresa así.

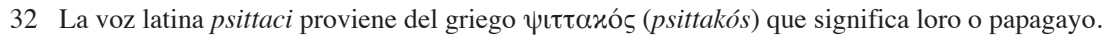

33 Cf. Nouveaux Essais, III 1 § 1, GP V 254.

34 Vid. Nouveaux Essais, III 6 § 12, GP V 286.

35 Vid. Herder, 2015, 32. 
papagayo y el estornino han aprendido suficientes sonidos lingüísticos, jamás han pensado una sola palabra humana. ${ }^{36}$

Así pues, Leibniz concluye que sólo el hombre tiene la posibilidad "de servirse de esos sonidos como signos de concepciones interiores, con el fin de que por medio de ellos puedan ser manifestadas a los demás". ${ }^{37}$ Es una posibilidad porque hay personas poco inteligentes que apenas manifiestan un remedo de habla, repitiendo los sonidos que escuchan sin tener la más mínima idea de lo que quieren decir.

Sucede con frecuencia que los hombres aplican sus pensamientos más a las palabras que a las cosas, y existen no sólo niños, sino hombres hechos y derechos, que hablan como papagayos, porque han aprendido la mayor parte de las palabras sin haber sabido antes las ideas que significan. ${ }^{38}$

En tales casos, aunque la emisión verbal se ciña a la fonética y a las reglas sintácticas de la lengua, las palabras se limitan a cubrir un hueco que no es ocupado por ningún pensamiento. Debido a ello, el hablante parece parodiar el habla humana, conduciéndose como una especie de "trujimán de pensamientos" (le trucheman des pensées) o como una suerte de "portador del habla de otra persona" (le porteur de la parole d'autruy). Pues se limita a reproducir las palabras, vacías de pensamiento, poniéndolas en circulación como moneda corriente, sin comprender lo que dicen. Se comporta entonces como un autómata lingüístico para quien las palabras no son objeto de intelección sino de mera manipulación. ${ }^{39} \mathrm{Y}$ así la palabra se reduce a un flatus vocis, a un ruido que emana de la boca y que se agota en su dimensión acústica, de forma similar al sonido que producen los papagayos cuando imitan las voces humanas. ${ }^{40}$ En tal caso, las palabras sustituyen por completo al pensamiento.

En suma, el psitacismo es un fenómeno psíquico y lingüístico en el que se articulan palabras sin pensarlas, entregándose a un vacuo automatismo verbal. En cuanto tal, se trata de una forma preteórica de cogitatio symbolica que anuncia lo que en lógica y matemática se aprecia de forma mucho más clara, precisa y diferenciada como un cálculo simbólico.

\subsection{Pensamiento ciego}

La contraposición entre cognitio symbolica y cognitio intuitiva resulta especialmente reveladora cuando Leibniz se refiere a la primera como pensamiento ciego (cogitatio caeca), empleando una metáfora visual que alude a una deficiencia intuitiva del espíritu. Liga así indisolublemente además ceguera eidética con uso de signos. ${ }^{41}$ Pues, a causa de la incapacidad de nuestra mente para contemplar de forma simultánea el contenido de las

36 Vid. Herder, 2015, 36.

37 Nouveaux Essais, III 1 § 2, GP V 254/Leibniz, 1977, 322. Según Locke, únicamente el hombre está facultado para generar sonidos articulados como signos de sus concepciones internas (signs of internal conceptions) y para comunicarlas, mediante esos sonidos, a sus congéneres (cf. Vid. Essay III 1 § 1-2/Locke, 1979, 476).

38 Nouveaux Essais, III 2 § 4, GP V 265/Leibniz, 1977, 337-338.

39 Leibniz dice que en tal caso se comporta como si fuera una letra (vid. Nouveaux Essais, III 2 \$2).

40 Sobre el nominalismo, vid. Nouveaux Essais, III 6 § 32, III 8 § 1.

41 Cf. Meditationes de cognitione, veritate et ideis, AA VI, 4B, 587. 
nociones complejas, el pensamiento se ve obligado, por decirlo así, a dar una especie de rodeo simbólico, recurriendo a los signos para compensar su falta de perspicacia intuitiva. Así es como la función compensatoria de los signos redunda en su utilidad, ya que proveen un filum mechanicum al que la mente puede aferrarse confiadamente a fin de no extraviarse en sus indagaciones.

Con todo, nuestra limitación intuitiva explica además el hecho de que el pensamiento, cuando opera con signos, permanezca casi siempre hueco, puesto que los símbolos son formas vacías que necesitan ser llenadas de significado. Del mismo modo, la finitud de nuestra intuitio permite entender por qué la cogitatio caeca es un requisito psicológico indispensable para el correcto funcionamiento del formalismo. Pues, cuando es llevado a su extremo, el formalismo reemplaza por completo el razonamiento contentual (en el que se razona con significados e ideas) por una especie de juego de fórmulas sin contenido semántico. Y esta clase de manipulación sintáctica de símbolos es, desde un punto de vista psicológico, una forma de cogitatio caeca lógica y reglada.

\subsection{Pensamiento sordo}

Leibniz utiliza también la expresión pensée sourd para referirse al pensamiento simbólico. De manera análoga a lo que sucede con la expresión cogitatio caeca, encontramos aquí una clara referencia a una deficiencia sensitiva, a una forma de privación auditiva que convierte el pensar en algo sin contenido. Leibniz dice por eso que el pensamiento es sordo cuando carece de percepción y sentimiento (vuide de perception et de sentiment), ${ }^{42}$ por lo cual apenas es audible, ya que en su interior está como hueco. ${ }^{43}$ Así, la mente no tiene más remedio que procesar y manipular signos vacíos de pensamiento y significado, haciendo abstracción, por ende, de cualquier elemento semántico, ignorando todo aspecto que no sea puramente formal y sintáctico.

Hay que tener en cuenta, en todo caso, que el uso del término sordo en este contexto se relaciona con la tradición matemática griega, en particular con la teoría aritmético-musical pitagórica y con el descubrimiento de las magnitudes inconmensurables. Los pitagóricos,

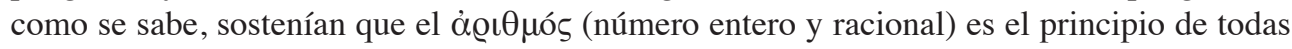
las cosas. Descubrieron, además, la existencia de relaciones puramente aritméticas en la escala musical, asociando los razones 1/2, 2/3, 3/4 a las relaciones musicales de la octava, la quinta y la cuarta, respectivamente. ${ }^{44}$ Por tanto, según esta concepción griega, los sonidos se relacionan entre sí conforme a un $\lambda$ ó ${ }_{0}$ s, del mismo modo que un número se relaciona con otro según una ratio. Para la concepción aritmético-musical pitagórica tiene sentido,

42 Cf. Nouveaux Essais, II 21 § 35, GP V 173.

43 Es lo que pasa, según Leibniz, cuando se piensa en la virtud, ya que se trata de una noción allende los sentidos y, por eso, apenas puede "llenarse" de contenido sensible. El problema, en el ámbito del razonamiento práctico, es que esta clase de pensamiento insensible no tiene suficiente fuerza como para motivar y conmover si la persona carece de una sólida base de cultura moral (cf. Davidson, 2005, 245).

44 Pitágoras descubrió la correspondencia entre el mundo abstracto de los sonidos musicales y el mundo abstracto de los números. La importancia de este descubrimiento se debe al hecho de que fundar los intervalos musicales sobre una base aritmética no sólo supuso el comienzo de la teoría musical sino el inicio de la ciencia misma (cf. James, 1995, 35-37). 
por ende, afirmar que un número irracional es sordo en la medida en que no le corresponde ningún sonido musical. ${ }^{45}$

Puede sostenerse entonces que el pensamiento es sordo cuando la mente ignora el significado de las palabras o de los símbolos que cubren los pensamientos, porque, al estar vacíos de inteligencia, son incapaces de hacerse oír, de modo que tampoco pueden escucharse. Desprovistos de significado actual in mente, el espíritu sólo se ocupa, pues, del correcto encadenamiento sintáctico de los signos. Y así, tal como el pensamiento ciego consiste en pensar sin ver la idea, el pensamiento sordo consiste en pensar sin escuchar el significado y, por ende, sin comprender qué quieren decir los signos más allá de su dimensión acústica, sintáctica y formal. Puede apreciarse, por tanto, la afinidad existente entre dicha forma de pensamiento y el formalismo, ya que, si los signos se consideran meras formas vacías, el pensamiento que trabaja con ellos tiende a ser sordo y a estar vacío de inteligencia, de modo que las operaciones simbólicas se asemejan, después de todo, a un mero juego de fórmulas con caracteres sin contenido.

\subsection{Pensamiento supositivo}

Leibniz declara que el conocimiento humano es, en su mayor parte, confuso o supositivo (confuses ou bien suppositives), ${ }^{46}$ porque los hombres casi siempre se limitan a suponer que saben algo en lugar de saberlo de verdad. Suponen o creen entender una cosa sin tomarse el trabajo de comprobar su creencia o suposición. Y así basan sus afirmaciones en una confianza desmesurada en lo que, implícita o explícitamente, ${ }^{47}$ creen o suponen saber. De donde resulta una cognitio ex hipothesi que no difiere cualitativamente de la que se halla en las nociones ocultamente imposibles (notions occultement impossibles), lo cual plantea un serio problema cognoscitivo. ${ }^{48}$

Ahora bien, de manera análoga a la comparación entre cognitio symbolica y cognitio intuitiva, Leibniz contrapone notio suppositiva y notio intuitiva. ${ }^{49}$ Pues la suppositio acaba casi siempre subrogando a la intuición a causa de la intrínseca finitud de nuestra intuitio..$^{50}$ No es de extrañar, por tanto, que Leibniz considere la cognitio suppositiva la forma humana de conocimiento por defecto. A fin de cuentas, la manera supositiva de concebir (maniere suppositive de concevoir) es siempre la misma, con independencia de que uno se haya cerciorado previamente de la posibilidad de las nociones consideradas. ${ }^{51}$

45 Hay que recordar además que $\lambda o ́ \gamma o s$ significaba para los griegos tanto lenguaje y habla como razón.

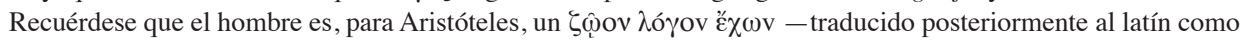

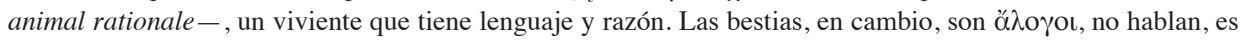
decir, son mudas e irracionales.

46 Cf. Discours de métaphysique, § 24, AA VI, 4B, 1568/OFC 2, 189.

47 La suppositio es casi siempre implícita, pero en el entimema, como silogismo abreviado, la suposición se hace explícita cuando el entimema es reconocido expresamente como tal. Por el contrario, cuando el razonamiento es entimemático, sin que uno sea consciente de que lo es, el razonamiento es supositivo, ya que se omiten premisas y en su lugar se ponen implícitamente suposiciones sin darse cuenta de ello.

48 Cf. Discours de métaphysique, § 25, AA VI, 4B, 1569/OFC 2, 190.

49 Vid. De arte characteristica ad perficiendas scientias ratione nitentes (¿1688?), AA VI, 4B, 912.

50 Leibniz habla por eso de cognitio caeca sive suppositiva (vid. AA VI, 4B, 1815).

51 Cf. Discours de métaphysique, § 25, AA VI, 4B, 1570/OFC 2, 190. 
Puede apreciarse entonces por qué la cognitio suppositiva se encuentra estrechamente vinculada con la teoría de las ideas de Leibniz, así como con su doctrina del inconsciente..$^{52}$ En efecto, el filósofo distingue expresamente idea de pensamiento,,$^{53}$ puesto que son cualidades del alma que tienen un modus essendi diferente. Así, los pensamientos son acciones, mientras que las ideas son hábitos o disposiciones que expresan naturalezas, formas o esencias. ${ }^{54}$ Las ideas tienen un fundamentum in natura, ya que, se piense en ellas o no, son independientes de los nombres y, por ende, no son arbitrarias. ${ }^{55}$

Análogamente, Leibniz distingue también las ideas de las nociones o conceptos. Pues, debido a que la idea es el objeto del pensamiento, no su forma, ${ }^{56}$ puede ser anterior y posterior a los pensamientos. ${ }^{57}$ Las nociones, en cambio, expresan lo que efectivamente concebimos o formamos, ${ }^{58}$ de modo que no siempre representan algo posible. El pensamiento, por tanto, se caracteriza por ser efímero y fluctuante, mientras que la idea se distingue por ser perdurable e indeleble, ya que "está siempre en nosotros, pensemos en ella o no". ${ }^{59}$ Tener una idea significa entonces poder pensar en ella siempre que se dé la ocasión, aunque no la pensemos actualmente. ${ }^{60}$ De este modo, las ideas pueden existir en la mente como simples disposiciones o virtualidades sin entrar jamás en la conciencia.

Como ejemplo de cogitatio suppositiva Leibniz suele citar el quiliógono - polígono de mil lados iguales - , porque, cuando pensamos en él, acostumbramos a cubrir su definición con la palabra, eximiéndonos así de considerar expresamente polígono ${ }^{61}$ (y lo que éste significa), lado, igual y mil. Gracias a ello, nos libramos también de intuir explícitamente esas nociones (explicate intueri).$^{62}$

En suma, la cognitio suppositiva es una forma de conocimiento en la que no hay contemplación actual de ideas. Se caracteriza también por su ambivalencia, ya que en ciertos casos puede ser útil, mientras que en otros puede llevar irremediablemente al error. En efecto, es sumamente útil cuando las suposiciones están bien fundadas y pueden emplearse operativamente con el fin de abreviar procesos cognitivos y ahorrar gasto mental. Pero cuando la suppositio no es suficientemente sólida o cuando los símbolos que subrogan el pensamiento contentual y la aprehensión eidética no son idóneos, conduce invariablemente a la equivocación. Como señala Belaval, ${ }^{63}$ el pensamiento puede permanecer supositivo, sin pérdida de certeza, a condición de que se acepten los términos de manera hipotética. En tal

52 Leibniz postula que gran parte de nuestra vida mental (percepciones, pensamientos, afecciones, apetitos, hábitos) corre por cauces inconscientes.

53 Cf. Nouveaux Essais, II 1 § 23, GP V 108.

54 Cf. Nouveaux Essais, II 1, § 1, § 26, GP V 99.

55 Cf. Discours de métaphysique, § 24, AA VI, 4B, 1569/OFC 2, 190; Nouveaux Essais, I 1 § 23, § 26, GP V 108109.

56 Leibniz alega que, si no fuera así, la idea surgiría y cesaría junto con los pensamientos efectivos que le corresponden. Vid. Quid sit Idea, AA VI, 4B, 1370.

57 Vid. Nouveaux Essais, II 1 § 1, GP V 99.

58 Vid. Discours de métaphysique, § 27, AA VI, 4B, 1572.

59 Discours de métaphysique, § 26, AA VI, 4B, 1570/OFC 2, 191.

60 Cf. Meditationes de cognitione, veritate et ideis, AA VI, 4B, 588; Quid sit Idea, AA VI, 4B, 1370.

61 Un polígono es una porción del plano delimitada por líneas rectas.

62 Vid. Gensini, 1992, 116.

63 Belaval 1960, 159. 
caso, se procede ex concessis, admitiendo provisionalmente las suposiciones, a la espera de su posterior validación y de que se demuestre ulteriormente la consistencia de las nociones implicadas.

\section{Matemática, filosofía y pensamiento simbólico}

Hemos esgrimido que el éxito del pensamiento simbólico depende del dominio cognitivo en que se use y del tipo de simbolismo empleado. Estos factores son decisivos cuando se trata de explicar por qué la matemática se erige como un coloso de la razón, mientras que la metafísica - con su afán de cientificidad siempre frustrado - parece condenada irremediablemente al fracaso. Es lo que veremos con más detalle en las siguientes secciones.

\subsection{Matemática, filosofía y experiencia}

Si algo distingue a la matemática de la filosofía es la manera en que se relaciona con los sentidos y cómo se aplica a la experiencia. Desde antiguo se ha reconocido la naturaleza inteligible de la matemática, así como su íntima vinculación con lo sensible. De ahí la estrecha conexión entre matemática e imaginación, facultad que, tradicionalmente, se ha considerado una especie de híbrido entre sensación y pensamiento. En efecto, Aristóteles ya situaba la phantasía entre la aísthesis y la nóesis. ${ }^{64}$ Posteriormente, la tradición filosófica moderna le ha asignado, como a la matemática misma, una posición intermedia entre el sentido y la razón, actuando así como enlace entre lo sensible y lo inteligible.

En lo esencial, Leibniz comparte esta opinión. Las ciencias matemáticas puras se ocupan de ideas claras y distintas que dependen de la imaginación, aunque requieren el auxilio del entendimiento. En caso contrario, no serían más que inducción. La matemática es, por tanto, para Leibniz ciencia de entia imaginaria. ${ }^{65}$

La metafísica, en cambio, es otra cosa. Sus conceptos son nociones puramente inteligibles que proceden de la reflexión del espíritu sobre su propia naturaleza, de donde surge el ser, la sustancia, la unidad, la identidad, la causa, la percepción, el razonamiento y una gran cantidad de nociones que los sentidos son incapaces de proporcionar. ${ }^{66}$ Por eso Leibniz afirma que la reflexión es para nosotros "la madre de las ciencias". ${ }^{67}$

No obstante, junto con defender la aprioridad del alma misma y de sus afecciones, ${ }^{68}$ el filósofo germano sostiene también que nada hay en el espíritu que no provenga de los sentidos. ${ }^{69}$ No existen, en efecto, pensamientos tan abstractos que no incluyan algo sensible..$^{70} \mathrm{Y}$ es justo aquí donde la matemática aventaja de forma decisiva a la metafísica, porque en ella

64 Cf. Aristóteles, De Anima III 3.

65 Cf. Mcrae, 1995, 182-186.

66 Vid. Nouveaux Essais, II 1 § 2, GP V 100-101; Monadología, § 30, GP VI 611-612; Leibniz, $1989,114$.

67 Leibniz a la reina Sofía Carlota (Hannover, 8 de mayo de 1704)/Leibniz, 1989, 128.

68 Vid. Leibniz, 1989, 114 y Nouveaux Essais, II 1 § (GP V 100), donde se encuentra la célebre fórmula: nihil est in intellectu, quod non fuerit in sensu, excipe: nisi ipse intellectus.

69 Vid. Nouveaux Essais, II 1 § 2, GP V 100.

70 Leibniz, 1989, 119. 
"la experiencia puede garantizar el razonamiento en todo momento". ${ }^{71}$ Euclides, de hecho, suele demostrar, mediante la razón, lo que ya puede verse suficientemente por experiencia y a través de imágenes sensibles. ${ }^{72}$ La matemática dispone, en este sentido, de mecanismos útiles y cómodos para comprobar sus proposiciones y corregir sus razonamientos ad libitum.

En las ciencias demostrativas como la aritmética, la geometría y la mecánica los sentidos son muy necesarios para tener ciertas ideas de las cosas sensibles, y las experiencias son necesarias para establecer ciertos hechos, e incluso útiles para verificar los razonamientos a modo de prueba. ${ }^{73}$

La equivocación, sin embargo, es algo bastante común fuera de la matemática. En física, tras muchos razonamientos, la experiencia suele refutar la conclusión, sin corregir, empero, el razonamiento y sin indicar tampoco dónde ha ocurrido exactamente el error. La situación es peor en metafísica y moral, donde casi siempre es imposible realizar experiencias en las conclusiones salvo de forma muy vaga. Además, en cuestiones estrictamente metafísicas, la experiencia suele ser imposible de llevar a cabo en esta vida. ${ }^{74}$ En metafísica y moral, por lo tanto, no se da el paralelismo entre razones y experiencias que encontramos en matemática, ${ }^{75}$ pues en ésta, en virtud de tal analogía, lo abstracto puede ser sensibilizado poniéndolo ante oculos mediante caracteres. ${ }^{76}$ Debido a ello, la matemática dispone de un filum cogitandi mechanicum que le permite operar sin tener que molestarse en contemplar las ideas, amén de que puede detectar los errores por medio de una simple inspección ocular. Y, en caso de disputa, en matemática se puede ver literalmente quién tiene realmente la razón. Este es el motivo por el cual la matemática puede explotar con tanto provecho la capacidad de la mente para pensar de forma automática con signos sensibles vacíos de contenido semántico.

\subsection{Cálculo y pensamiento simbólico}

Leibniz se dio cuenta de la existencia de diversos tipos de razonamiento que observan, cada uno a su modo, escrupulosamente la forma lógica. Pues la lógica aristotélico-escolástica, la geometría euclidiana e incluso las argumentaciones de los jurisconsultos romanos, a pesar de sus diferencias, se ciñen a un formalismo constante. ${ }^{77}$ Así, una cuenta bien hecha, un cálculo algebraico o un análisis de infinitesimales son argumentos en forma, ya que, habiéndose demostrado previamente la corrección de su manera de razonar, uno puede estar seguro de no equivocarse con ellos. ${ }^{78}$ A Leibniz esto le confirma que esas formas de argumentación son indicios y desarrollos parciales de una lógica mucho más abstracta y universal

71 Nouveaux Essais, IV 2 § 12, GP V 352/Leibniz, 1977, 445.

72 Cf. Nouveaux Essais, Prefacio, GP V 43.

73 Leibniz, 1989, 116.

74 Cf. AA VI, 4B, 205.

75 Vid. Nouveaux Essais, IV 2 12, GP V 352.

76 Vid. Analysis linguarum, 1678, AA VI, 4B, 102.

77 Incluso se encuentran rastros de formalismo constante en la "matemática natural" (Mathematique naturelle) de los campesinos (vid. Nouveaux Essais, IV 16 9, GP V 447).

78 Nouveaux Essais, IV 17 \$, GP V 461. 
que, como arte del pensamiento (Denckkunst) ${ }^{79} \mathrm{y}$ técnica general del razonamiento cierto e infalible, no sólo es un ars iudicandi para juzgar lo que tenemos delante, sino, sobre todo, un ars inveniendi que ha de procurar el descubrimiento de lo que aún desconocemos.$^{80} \mathrm{En}$ cuanto tal, se asemeja a un álgebra cogitativa universal que permite razonar acerca de todo lo susceptible de determinaciones precisas. ${ }^{81}$

Ahora bien, aun cuando ya es posible razonar ciegamente con lenguas naturales antes de la ciencia, son realmente la lógica y la matemática las que desarrollan la disposición simbólica de la mente como un calculus, usando el lenguaje lógico-matemático como modelo. Las lenguas naturales, en efecto, tienen la desventaja de que no se comportan como un cálculo preciso e infalible, ya que los errores en la construcción de palabras y los fallos en el razonamiento no pueden expresarse como faltas sintácticas. En lógica y matemática, en cambio, los errores de razonamiento están ligados a la sintaxis de los signos. ${ }^{82}$

Así, inspirándose en Hobbes, Leibniz establece un nítido paralelismo entre razonamiento y cálculo, hasta el punto de equipararlos. La analogía está justificada en la medida en que para él cogitatio symbolica y cálculo van de la mano. Pues el pensamiento simbólico se distingue por su capacidad para procesar signos de manera semiautomática, mientras que un calculus es una operatio per caracteres que produce relaciones sígnicas mediante la transformación de fórmulas (transmutaciones formularum), observando reglas fijas previamente demostradas. ${ }^{83}$ Por eso Leibniz considera que el perfeccionamiento del razonamiento tiene que lograrse a través de su conversión en una manipulación reglada y algebraica de caracteres idóneos, a fin de que todo fallo cognitivo equivalga a una especie de error computacional (idem error animi qui calculi) ${ }^{84}$ Leibniz pretende desarrollar, de este modo, la facultad cogitativa simbólica como técnica computacional, antecedente remoto, no sólo de la lógica matemática, sino también de la informática y de la inteligencia artificial en su enfoque clásico.

\subsection{Pensamiento simbólico, método característico y método verbal}

Leibniz insiste en que la cogitatio symbolica supone una ventaja solamente en determinados dominios cognitivos y cuando se cumplen ciertas condiciones. Esto se debe a que lo que se presenta como una fortaleza en un contexto epistémico suele constituir una debilidad en otro y viceversa. El reto consiste, por tanto, en idear una forma de beneficiarse de las ventajas de la cognitio symbolica sin padecer sus inconvenientes. Porque entonces podría procederse a ciegas y de manera algorítmica sin preocuparse por la consistencia del razonamiento. Como afirma Leibniz, "si alguna vez fuéramos conscientes de haber ordenado las palabras distinta e invariablemente, bastaría con emplear pensamientos ciegos para razonar con distinción". 85

79 Vid. Carta a Gabriel Wagner (1696), GP VII 516.

80 Cf. GP VII 516.

81 Vid. Couturat, 1901, 319-320.

82 Cf. Fundamenta calculi ratiocinatoris, AA VI, 4B, 919.

83 Vid. Fundamenta calculi ratiocinatoris, AA VI, 4 B, 921.

84 Cf. Fundamenta calculi ratiocinatoris, AA VI, 4 B, 919.

85 Demonstratio propositionum primarum, AA VI, 2, 481. 
Ahora bien, la clave para conseguirlo reside en disponer de caracteres adecuados, pues, en tal caso, los signos "pensarían" por nosotros y podríamos dejar la validación eidética de las expresiones simbólicas para el final del razonamiento. El método característico (methodus per meros characteres) reúne estas exigencias, ya que expurga la cognitio symbolica de sus deficiencias, al tiempo que retiene sus fortalezas.

Los trabajos de característica geométrica de Leibniz ilustran bastante bien las virtudes de dicho método. Así, cuando se trata de razonar en geometría, supera al método verbal porque expresa una figura sólo con caracteres, sin apoyarse ni en palabras ni en figuras auxiliares. El método verbal (methodus per verba), en cambio, a la hora de expresar una figura, se sirve únicamente de palabras, sin recurrir a otros caracteres ni a otras ayudas. ${ }^{86}$

El método característico, asimismo, aventaja al método verbal porque, en el transcurso de la operación o del cálculo, "la mente no piensa en la cosa que investiga", 87 lo cual redunda en un menor coste cognitivo. A ello hay que agregar el hecho de que no necesita percibir constantemente el procedimiento por el cual se pasa gradualmente a nuevas verdades. Así, debido a que trabaja de forma análoga al álgebra - incluso sin disponer del auxilio de figuras como la geometría-, el método característico puede manipular los signos cómoda y ciegamente con excelentes resultados e invirtiendo poco esfuerzo mental. Pues, debido a que no hace falta pensar en el asunto estudiado, el razonamiento puede desarrollarse de manera prácticamente automática, generando un superávit de energía mental que puede reconducirse a procesos cognitivos de nivel superior. Esto supone una ventaja importante en lo que respecta a la invención, amén de que no conlleva pérdida alguna de seguridad y rigurosidad. 88

Otra ventaja importante del método característico es que su eficacia no depende de ningún tipo de cualificación especial de los individuos que lo usan. Precisamente por ello "es útil cuando se confía una investigación a algún otro y prescribimos ese método cuando podemos usar personas que no entienden absolutamente nada de la cosa tratada". ${ }^{89}$ Así, los éxitos cosechados pueden atribuirse casi exclusivamente al método y no a las aptitudes de los sujetos que lo aplican, hasta el punto de que puede usarlo incluso una mala cabeza. Pero, en caso de que lo utilicen personas de ingenio sobresaliente, los resultados pueden ser aún más impresionantes ${ }^{90}$

El método característico, igualmente, es más idóneo en ciencia, porque el método verbal tiene el inconveniente de la anfibología. En efecto, al usar palabras comunes (methodus per verba vulgaria), las conexiones, las transiciones y las consecuencias que establece suscitan diversas ambigüedades. En cambio, debido a la simplicidad de sus caracteres, al método característico le basta con apoyarse en letras y en "algunas figuras como las de congruencia, igualdad, proporción, razón, similitud y coincidencia", ${ }^{11}$ de lo cual resultan pocos malentendidos y confusiones.

86 Vid. Leibniz, 1995, 46. Ambos se oponen al método euclidiano, pues éste utiliza figuras construidas con regla y compás. Las figuras tampoco tienen para Leibniz valor apodíctico sino meramente heurístico (vid. Nouveaux Essais, IV 1 § 9, GP V 341-342/Leibniz, 1977, 433).

87 Leibniz, 1995, 47.

88 Vid. Nouveaux Essais, IV 3 § 30 , IV 1 \$ 9.

89 Leibniz, 1995, 47.

90 Vid. GP VII 518-519.

91 Leibniz, 1995, 48. 
Por lo demás, frente a la prolijidad y lentitud del método verbal, el método característico ofrece brevedad (via per caracteres brevior est), ya que es más fácil decir y escribir, por ejemplo, AB que abscisa.92 Con la ventaja adicional de que resulta mucho más conciso y cómodo usar la pluma y el papel cuando se tiene ante la vista el catálogo de las letras. ${ }^{93} \mathrm{Y}$ si a ello añadimos las virtudes distintivas de los caracteres, se entiende la superioridad que Leibniz atribuye al método característico frente al método verbal.

Así pues, de lo anteriormente expuesto puede inferirse que el método característico es, en conjunto, el más indicado para la ciencia, especialmente cuando se rige por el ideal matemático de conocimiento y cuando además no se tiene en cuenta la especificidad de cada saber. Sin embargo, cuando se presta atención a la peculiaridad de cada ciencia surgen excepciones importantes. Así, debido a que en filosofía, sobre todo en metafísica, es indispensable pensar en la cosa que se investiga, la prolijidad y la lentitud del método verbal parecen ajustarse más a su forma específica de conocer. Análogamente, a causa de que en metafísica no se puede hacer tabula rasa del significado de los términos ni de la posibilidad de las nociones, no parece ser lo más apropiado aplicar en ella el método característico y el tipo de cogitación en que se funda. En efecto, el pensamiento irreflexivo es una forma de "pensar como si no se pensara" debido a que "se piensa sin reflexión" (cogitare sed sine reflexione). Y este tipo de pensamiento no parece el más adecuado para la prima philosophia. ${ }^{94}$ Después de todo, si la reflexión es, como sostiene Leibniz, la esencia del espíritu (essentia Mentis), ${ }^{95}$ es justamente esa reflexio la que está presente en Euclides y la que, hasta ahora, ha faltado casi siempre en metafísica.

En suma, el método característico idóneo en lógica, matemática y ciencias afines, sobre todo en áreas rutinarias de investigación. Pero no puede afirmarse lo mismo - por lo menos no a la ligera - para la filosofía, especialmente la metafísica, donde la irreflexión y la ceguera eidética no tienen cabida por principio.

\section{A modo de conclusión}

La cogitatio symbolica es una forma de pensar que se caracteriza por su ceguera eidética y por su sordera semántica, rasgos que ya pueden apreciarse claramente en el psitacismo, lo cual sugiere que el pensamiento simbólico es anterior a la ciencia y dista de ser exclusivo de la lógica y la matemática. Pues la gente ya razona con lenguas naturales y se comporta a menudo como una simple máquina parlante en el ámbito de la vida preteórica, sirviéndose de palabras vacías sin tener presente su significado en la conciencia. ${ }^{96}$ Puede afirmarse, por tanto, que el psitacismo, con su distintivo automatismo verbal, anticipa a su manera el tipo de pensamiento que se encuentra en el cálculo simbólico, cálculo que desarrollan de manera científica y formal la lógica y la matemática.

Ahora bien, la cognitio symbolica se comprende mejor cuando se profundiza en el sentido de expresiones como cogitatio caeca y pensée sourd, puesto que lejos de ser casuales

92 Vid. Leibniz, 1995, 48.

93 Cf. Leibniz, 1995, 48.

94 Vid. Demonstratio propositionum primarum, AA VI, 2, 482.

95 Cf. Demonstratio propositionum primarum, AA VI, 2, 482.

96 Vid. Nouveaux Essais, II 21 § 35, GP V 171-172. 
(como sucede también con el término cognitio suppositiva), se fundan en una concepción de la mente que, como sucede siempre en Leibniz, hunde sus raíces en su epistemología y especialmente en su metafísica. En particular, se entiende mejor por qué el filósofo concibe su characteristica universalis desde una perspectiva ergonómica y funcional.

En este sentido, Leibniz tiene el mérito de haber abandonado por ilusoria la creencia en un contacto inmediato entre el entendimiento y su objeto, sin ningún tipo de mediación simbólica. Con todo, la tesis de la necesaria intermediación semiótica, cuando es llevada al extremo, tiende a conducir inexorablemente, como advierte Stiegler, a la tecnificación de la ciencia y, por ende, a una forma crónica y sistemática de ceguera eidética. ${ }^{97}$ Esto pone de relieve, asimismo, la existencia de cierto conflicto entre la concepción leibniziana del simbolismo y su teoría de las ideas. En efecto, la prevalencia de lo simbólico en detrimento de lo eidético, debido a la propensión de los signos a independizarse de las ideas, entraña el riesgo de una proliferación arbitraria y descontrolada de los símbolos. Leibniz, empero, pretende mantener a raya ese problema mediante el expediente de ligar los caracteres a la base realísima de las esencias lógicas. En su opinión, únicamente puede contrarrestarse la devaluación veritativa de los sistemas de signos, así como su pérdida de funcionalidad, arraigándolos firmemente a un substrato eidético. Porque, cuando no se presta debida atención al fundamentum in re de los símbolos, ni se cuenta con ningún tipo de control epistémico que impida su emancipación radical, se corre el peligro de que se expandan de manera totalmente autónoma y exorbitada.

Existe otra tensión en el seno del leibnizianismo que interesa destacar aquí: la que tiene lugar entre el matematismo de Leibniz y la pretensión de universalidad de su característica, por un lado, y la especificidad de la matemática y la filosofía como saberes racionales irreductibles, por el otro. Poca duda cabe de la idoneidad del método característico en lógica y matemática. De hecho, la influencia del enfoque lógico-característico de Leibniz se percibe sobre todo en la actualidad en algunas ramas de la tecnociencia más que en la filosofía propiamente dicha (con la excepción tal vez de cierta filosofía analítica). Pues la argumentación de índole lógico-apodíctica ha visto reducido paulatinamente su ámbito de influencia a ciertas esferas científicas y tecnológicas. Hoy en día, las restantes formas de razonamiento tienden a considerarse argumentos persuasivos que ya no pretenden ser irrefutables, puesto que buscan sobre todo dirigir al interlocutor hacia una especie de consentimiento en el que se dan cita diversos factores, no sólo de índole lógica. ${ }^{98}$ Además, hasta la fecha no existen métodos automáticos que, valiéndose únicamente de la lógica, sean capaces de evaluar, de manera eficaz e infalible, argumentos formulados originalmente en lengua vernácula. Por eso, aunque Leibniz soñó hace más de trescientos años con un método de ese tipo, su sueño sigue sin hacerse realidad. ${ }^{99}$ Así, en la medida en que el proyecto leibniziano de aplicar la characteristica y la lógica a los argumentos filosóficos continúe siendo sólo un sueño, la filosofía seguirá pensando y razonando, al menos durante mucho tiempo, con palabras del lenguaje natural.

97 Vid. Stiegler, 2002, 16.

98 Cf. Eco, 2011, 195.

99 Vid. Johnson-Laird, 2016, 142. 
De todos modos, aun cuando Leibniz vaticina en momentos de entusiasmo que las disputas filosóficas podrán zanjarse mediante el simple expediente de un cómputo, ${ }^{100}$ no hay que perder nunca de vista el hecho de que sus obras más importantes están escritas en latín, francés y alemán. Esto puede darnos una pista de las verdaderas intenciones del filósofo. Leibniz, en efecto, no pretende que se razone mecánica y ciegamente en metafísica. Más bien reclama para la filosofía la explicitación completa y exhaustiva del saber mediante símbolos adecuados, de modo que puedan exponerse, ante la mirada de la inteligencia, todos los elementos de la ciencia, sin omitir nada y sin asumir de manera implícita ningún tipo de supuesto. Aspira, en este sentido, al completo autoesclarecimiento del saber, a fin de volcar de manera sistemática, ordenada y por escrito todo lo que en el espíritu yace de forma oscura, desordenada y tácita. En resumidas cuentas, Leibniz no pretende convertir el razonamiento metafísico en un cálculo ciego y semiautomático; antes bien, quiere instaurar y desarrollar en metafísica lo que él llama la luz de todo filosofar (omnis philosophandi lux), que sólo Euclides, en su opinión, ha conseguido hacer realidad a su manera. Para Leibniz observar este ideal en metafísica es más urgente y necesario que en matemática, ya que se trata de la ciencia primera y arquitectónica.

De este modo, distanciándonos en parte de Leibniz, podemos afirmar que el modelo filosófico de la máxima transparencia y determinación del saber debería convertirse para la razón en faro e ideal regulativo, a fin de orientar la búsqueda incesante, siempre renovada, que desde sus orígenes ha distinguido a la metafísica como empresa intelectual que se pregunta incansablemente por el origen radical de las cosas, así como por su constitución esencial y su fin último.

\section{Referencias bibliográficas}

Arpaly, N. y Schroeder, T. (2018), In Praise of Desire, Oxford/Nueva York: Oxford University Press.

Aubenque, P. (2008), El problema del ser en Aristóteles. Ensayo sobre la problemática aristotélica, traducción de Vidal Peña, Madrid: Escolar y Mayo Editores.

Belaval, Y. (1960), Leibniz critique de Descartes, París: Gallimard.

Couturat, L. (1901), La logique de Leibniz d'après des documents inédits, Hildesheim: Georg Olms.

Davidson, J. D. (2005), «Video Meliora Proboque, Deteriora Sequor: Leibniz and the Intellectual Source of Sin», en: D. Rutherford y J. A. Cover (eds.): Leibniz: Nature and Freedom, Oxford/Nueva York: Oxford University Press, pp. 234-253.

Eco, U. (2011), La estructura ausente, traducción de Helena Lozano Miralles, Barcelona: Debolsillo.

Favaretti, M. (2007), Filum cogitandi. Leibniz e la conoscenza simbolica, introducción de Luigi Perissinotto, Milán: Mimesis Edizioni.

Herder, J. G. (2015), Herder, estudio introductorio de Pedro Ribas, Madrid: Editorial Gredos. Hobbes, T. (1996), Leviatán. La materia, forma y poder de un Estado eclesiástico y civil, traducción, prólogo y notas de Carlos Mellizo, Madrid: Alianza Editorial.

100 Cf. GP VII 200. 
James, J. (1995). The Music of the Spheres: Music, Science and the Natural Order of the Universe, Londres: Abacus.

Johnson-Laird, P. (2016). Cómo razonamos, traducción de María José Pozo Municio. Madrid: Antonio Machado Libros.

Leibniz, G. W. (2010), Obras filosóficas y científicas. Volumen 2: Metafísica, edición de Ángel Luis González, Granada: Editorial Comares.

Leibniz, G. W. (1970-2006), G. W. Leibniz: Sämtliche Schriften und Briefe, edición de la Academia Alemana de Ciencias de Berlín, Berlín: Akademie Verlag.

Leibniz, G. W. (1995), La caractéristique géométrique, texto, introducción y notas de Javier Echeverría, traducción de Marc Parmentier, París: J. Vrin.

Leibniz, G. W. (1989), Filosofía para princesas, prólogo, traducción y notas de J. Echeverría, Madrid: Alianza Editorial.

Leibniz, G. W. (1977), Nuevos ensayos sobre el entendimiento humano, edición preparada por J. Echeverría, Madrid: Editora Nacional.

Leibniz, G. W. (1971), Die mathematische Schriften (7 vols.), edición de C. I. Gerhardt, Hildesheim: Olms.

Leibniz, G. W. (1961a), Die philosophische Schriften (7 vols.), edición de C. I. Gerhardt, Hildesheim: Olms.

Leibniz, G. W. (1961b), Opuscules et fragments inédits de Leibniz: extraits des manuscrits de la Bibliothèque royale de Hanovre, edición de Louis Couturat, Hildesheim: Olms.

Locke, J. (1979), An Essay concerning Human Understanding, edición e introducción de Peter H. Nidditch, Oxford/Nueva York: Oxford University Press.

Mcrae, R. (1995), «The Theory of Knowledge», en: N. Jolley (ed.): The Cambridge Companion to Leibniz, Nueva York: Cambridge University Press, pp. 176-198.

Pombo, O. (1987), Leibniz and the Problem of a Universal Language, Münster: Nodus Publikationen,

Stiegler, B. (2002), La técnica y el tiempo (vol. I: el pecado de Epimeteo), traducción de Beatriz Morales Bastos, Hondarribia: Editorial Hiru. 